Elżbieta JASTRZĘBOWSKA

(Rzym, Stacja PAN)

\title{
ŚLADY GROMADZENIA OFIAR LUB DARÓW W PRZYKOŚCIELNYCH DOMACH W PTOLEMAIS I CYRENE?
}

Rzecz dotyczy swoistego rodzaju kamiennych instalacji w dwóch domach, które znajdują się w obu przypadkach koło kościołów, w samych centrach słynnych metropolii starożytnej Cyrenaiki - w Ptolemais (dziś Tolmeita) i w Cyrene (dziś Shahat) we wschodniej Libii. Instalacje te, nazywane tradycyjnie, aczkolwiek umownie, ,żłobami”, pochodzą z ostatniej fazy użytkowania obu domów. Ponieważ Ksiądz Profesor Stanisław Longosz jest znawcą późnego antyku i piśmiennictwa chrześcijańskiego, chciałabym poświęcić Mu kilka refleksji na temat może nie najpiękniejszych zabytków, ale z pewnością interesujących, bo nadal enigmatycznych, co do ich pierwotnej funkcji. Czynię to także w nadziei, że może to zainteresuje Jubilata i nuż w oparciu o swoją znajomość piśmiennictwa wczesnochrześcijańskiego pomoże nam archeologom rozświetlić wspomnianą zagadkę. Chodzi o dość duże kamienne bloki prostopadłościenne, wyżłobione w środku jednego z dłuższych boków i ustawione tym wyżłobieniem do góry, jeden blok za drugim w linii prostej. Zabytki te, swoim wyglądem przypominające rzeczywiście żłoby dla koni, spotykane są dość często na afrykańskich stanowiskach archeologicznych późnego antyku, tylko że bardzo rzadko pomieszczenia, w których występują, można rzeczywiście nazwać stajniami - jak to na przykład było w przypadku parteru wielkiego ksenodochionu w centrum pielgrzymek św. Kryspiny w Tebessie ${ }^{1}$. Przykłady „żłobów”, przetrwałych najczęściej w cywilnych budowlach publicznych i domach prywatnych, ale też w kompleksach przykościelnych, były dotąd znane z wykopalisk na wielu stanowiskach, przede wszystkim rzymskiej i bizantyjskiej Afryki Północnej, od Zana na zachodzie (dziś w Algierii) po Dougga (dziś w Tunezji), w tym głównie na obszarze przygranicznym między tymi obydwoma krajami. Literatura na ten temat zgromadziła się już ogromna; a interpretacji, do czego służyły owe „żłoby”, jest także sporo: rzeczywiste żłoby dla koni, pojemniki do zbierania przez władze cywilne annony w naturze w przypadku

${ }^{1}$ Por. J. Christern, Das frühchristliche Pilgerheiligtum von Tebessa, Wiesbaden 1976, 90-93, 239-244. 
budowli pogańskich, zaś w odniesieniu do kompleksów chrześcijańskich pojemniki do gromadzenia ofiar wiernych dla Kościoła lub odwrotnie, instalacje służące do charytatywnego rozdawnictwa produktów wiernym przez lokalne Kościoły ${ }^{2}$. Ostatnio zebrała to wszystko ponownie absolwentka Instytutu Archeologii Uniwersytetu Warszawskiego, mgr Agnieszka Karmańska, w swojej pracy licencjackiej przygotowanej pod kierunkiem prof. Federico Guidobaldiego w Papieskim Instytucie Archeologii Chrześcijańskiej w Rzymie ${ }^{3}$. Poznawszy, przy okazji niedawnych wykopalisk w Ptolemais, bliżej imponujące ruiny miast hellenistycznej, rzymskiej i bizantyjskiej Cyrenaiki, w trzech z nich natknęłam się na podobne ,żłoby”, które dotąd nie spotkały się z jakimkolwiek zainteresowaniem badaczy, a które mogą stać się ciekawym dodatkiem do bogatego katalogu Karmańskiej.

W Ptolemais ,żłoby” znajdują się w domu Paulosa (fot. 1), leżącym po północnej stronie zachodniego krańca słynnej Via Monumentale, późnoantycznej arterii miasta, biegnącej z zachodu (od łuku Konstantyna i Licyniusza) na wschód (do resztek anonimowego Tetrastylu), ulicy tak nazwanej od czasów przedwojennych wykopalisk włoskich ${ }^{4}$. Carl Kraeling, który w latach 50-tych ubiegłego wieku odkopał dom Paulosa, poświęcił tym instalacjom zaledwie jedno zdanie i uznał je za rzeczywiste żłoby dla koni, zaś zawierające je pomieszczenia za stajnie ${ }^{5}$. Dom Paulosa miał, jak to zwykle w Ptolemais, kilka faz swojej aktywności, od wczesnego okresu rzymskiego (I wiek) po wczesny bizantyjski (V wiek) ${ }^{6}$. W tej ostatniej fazie, zgodnie $\mathrm{z}$ inskrypcją znalezioną w zachodniej części domu, zamieszkiwał tu Paulos, wysoki urzęd-

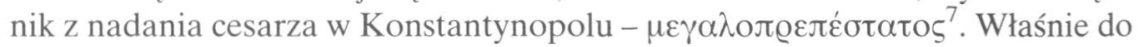
tego okresu istnienia domu należą wspomniane ,żłoby”, wykute w lokalnym wapieniu (ok. 1 x 0,50 x 0,50 m, fot. 2). Znajdują się one w północno-zachodnim narożniku domu: pięć sztuk (w tym jedna poważnie uszkodzona) w jednej linii ze wschodu na zachód, pomiędzy pomieszczeniami na planie Kraelinga nr 20 i 21 (na południu) i nr 23 (na północy) oraz jeden obiekt w murze

${ }^{2}$ Por. przede wszystkim: G.Ch. Picard, Civitas Mactariana. Karthago VIII, Tunis 1957, 137 146; N. Duval - J.C. Golvin, Haïdra à l'époque chrétienne IV: le monument à auges et les bâtiments similaires, „Comptes rendus de l'Académie des Inscriptions et Belles-Lettres” 1972, 133-172; N. Duval, Encore les «monuments à auges» d'Afrique, „Mélanges d'École Française de Rome” 88 (1977) 929-959.

3 Por. A. Karmańska, Le strutture dette „,mangiatoie” in edifici di età paleocristiana dell'Africa del Nord, Città del Vaticano 2007 - praca nie jest opublikowana, ale została udostępniona mi w wydruku komputerowym przez Autorkę, za co chciałabym Jej serdecznie podziękować.

${ }^{4}$ Por. przede wszystkim C.H. Kraeling, Ptolemais, City of the Lybian Pentapolis, Chicago 1962, 31, 74-83; S. Stucchi, Architettura Cirenaica, Roma 1975, 274, 338, 341, 446; Ptolemais. Archaeological Tourist Guide, Warsaw 2006, 38.

5 Por. Kraeling, Ptolemais, s. 155.

${ }^{6}$ Por. tamże, s. 156; Stucchi, Architettura Cirenaica, s. 221 i 305.

7 Por. Kraeling, Ptolemais, s. 211; Stucchi, Architettura Cirenaica, s. 493. 
północno-południowym, między pomieszczeniami nr 25 i 24, na północ od pomieszczenia $\mathrm{nr} 23^{8}$. Są one dziś oczywiście bardziej zniszczone niż były 43 lata temu, podczas wykopalisk Kraelinga, ale pozostały nadal jeszcze widoczne w odsłoniętych ruinach domu. Jeden ze „żłobów” na zachodnim końcu dłuższego ich ciągu (na południe od nr 21) ma wydrążone otwory na wylot, u dołu obu krótszych boków, tylko nie wiadomo, kiedy i w jakim celu otwory te zostały zrobione. W dzisiejszym stanie zachowania całej budowli przebieg murów poszczególnych pomieszczeń, zwłaszcza w tej części domu, nie jest dobrze widoczny na powierzchni ziemi. Według planu Kraelinga, pomieszczenia zawierające ,żłoby”, były dostępne od zewnątrz tylko w jednym miejscu, z ulicy na zachodzie przez dość wąskie drzwi i od wewnątrz, z południa przez drzwi ze schodkami, o co najmniej trzech stopniach prowadzących w dół z południowo-wschodniej części domu, gdzie mieściły się niewielkie termy domu? .

W każdym razie zacytowana wyżej „stajenna” interpretacja Kraelinga wydaje się raczej wątpliwa, bo trudno sobie wyobrazić, aby wspomniana para drzwi mogła służyć koniom za przejścia, tak jak mało przekonywująca jest identyfikacja wszystkich wymienionych, niewielkich pokoików tego domu jako stajnie. Dalszy ciąg na północ domu Paulosa, jak i w ogóle jego otoczenie, nie jest znane, tzn. nie zostało jeszcze odkopane. Jednak na sąsiedniej insuli od strony północno-wschodniej znajduje się z pewnością niewielki, choć jeszcze nieodsłonięty kościół. Jego położenie - z apsydą skierowaną na południe - jak i wyjątkowy na terenie Cyrenaiki kształt - krzyża wpisanego w prostokąt (22,50 x $18 \mathrm{~m}$ ) z czterema małymi pomieszczeniami w narożnikach budowli - są dziś znane dzięki magnetometrycznym badaniom Krzysztofa Misiewicza przeprowadzonym w 2007 roku $^{10}$.

W Cyrene mamy natomiast do czynienia z dziewięcioma lepiej zachowanymi ,żłobami” (fot. 3), które stoją w jednym ciągu, w dużym pomieszczeniu o planie prostokąta, należącym do dużego rzymskiego domu prywatnego z perystylem ${ }^{11}$. Tutaj, podobnie jak w Ptolemais, dom ten miał też kilka faz użytkowania, począwszy od okresu hellenistycznego aż po V wiek. Wspomniane pomieszczenie pochodzi, również i w tym przypadku, z ostatniej fazy aktywności domu i znajduje się w jego północnej części, zaraz na południe od wschodniego narożnika chrześcijańskiej Bazyliki Centralnej z VI wieku, a naprzeciwko

\footnotetext{
${ }^{8}$ Por. Kraeling, Ptolemais, fig. 51 i 55; Stucchi, Architettura Cirenaica, s. 493.

9 Por. Kraeling, Ptolemais, fig. 55.
}

${ }^{10}$ Por. E. Jastrzębowska, Some open questions concerning Late Antique, Early Christian and Byzantine Ptolemais, (w druku); taż, Le basiliche cristiane sconosciute nel centro città di Tolemaide. Akta sesji pt. „Archeologia a Tolemaide” (Rzym, 27-28 maja 2008), (w druku).

11 Por. R.G. Goodchild, Kyrene und Apollonia, Zrich 1971, 143-144; Stucchi, Architettura Cirenaica, s. 492; R.M. Bonacasa Carra, Le Case del Quartiere Centrale, w: Cirene, Milano 2000, 155, nr 67 na planie Cyrene na stronie 39. 
niewielkich term przykościelnych ${ }^{12}$. Ani te „żłoby”, ani pomieszczenie je zawierające, poza krótką wzmianką i to bez cienia wątpliwości, że chodzi tutaj o stajnie ${ }^{13}$, nie były dotąd publikowane. „Żłoby” stoją w jednej linii, jeden za drugim, pośrodku prostokątnego pomieszczenia wzdłuż jego dłuższej osi i są wykute w lokalnym wapieniu, praktycznie są one takie same, jak w Ptolemais. Teoretycznie po obu stronach ,żłobów” mogłyby zmieścić się stojące konie, ale pomieszczenie jest dostępne w jego południowo-wschodnim narożniku wyłącznie poprzez schody (o co najmniej pięciu stopniach), prowadzące od drzwi w dół na kamienną podłogę tej domniemanej stajni. Zatem i w tym przypadku trudno sobie wyobrazić wprowadzanie i wyprowadzanie koni po schodach, czy też zmuszanie ich do przeskakiwania przez ,żłoby”, aby mogły luźniej stać z drugiej strony linii tych urządzeń kamiennych.

Podobne wątpliwości dotyczą jeszcze jednego założenia ze „żłobami”, które w ogóle nie jest nawet wzmiankowane w literaturze fachowej, ale stanowi interesujący materiał porównawczy dla omawianych zabytków. Chodzi o krótki rząd czterech ,żłobów” (fot. 4) w niewielkim prostokątnym pomieszczeniu, być może dobudowanym później - jak się wydaje na pierwszy rzut oka - do pólnocnego boku dużego dziedzińca, wchodzącego w skład kompleksu świętego boga Asklepiosa w El Bayda/El Beida (antyczne Balagrae) również w Cyrenaice. Wykopaliska tam przeprowadzone w latach pięćdziesiątych ubiegłego stulecia nie doczekały się jeszcze pełnej publikacji. Początki tego sakralnego kompleksu pogańskiego sięgają jeszcze epoki hellenistycznej (IV-III wiek prz. Chr.), ale przetrwałe ruiny datuje się na poł. II wieku (panowanie Hadriana) ${ }^{14}$. Można jednak przypuszczać, że to sanktuarium tak bardzo popularnego w antyku boga Zdrowia, było jeszcze aktywne również później, co powszechnie miało miejsce w wielu innych Asklepieionach świata starożytnego. W teatrze przyległym do sanktuarium znaleziono w 1956 r. skarb 259 brązowych monet, w większości z poł. IV wieku ${ }^{15}$. Zatem najwyraźniej w późnym antyku udawali się tam nadal pielgrzymi, chorzy naprawdę lub tylko z urojenia, aby słynnym nocnym pobytem (incubatio) wybłagać u Asklepiosa uzdrowienie. Cztery ,żłoby" znajdują się w jednym z ostatnich, niewielkich pomieszczeń,

12 Por. Goodchild, Kyrene und Apollonia, s. 143.

13 Por. tamze, s. 143; Sandro Stucchi (Architettura Cirenaica, s. 492) podaje, że Goodchild wyrażał się ustnie mniej kategorycznie na ten temat i proponował interpretację tego pomieszczenia jako farbiarni z niewielkimi basenami zamiast ,żłobów”. Rosa Maria Bonacasa Carra pisze natomiast o „żłobach” w kontekście innego domu w tej części miasta, tzw. Domu Dominy Spaty, zob. Bonacasa Carra, Le Case del Quartiere Centrale, s. 155.

${ }_{14}$ Por. H. Sichtermann, Archäologische Funde und Forschungen in der Kyrenaika 1942-1958, „Archäologische Anzeiger” 1959, 326-335; Stucchi, Architettura Cirenaica, s. 103 i 263-266.

15 Por. R.G. Goodchild, A coin-hoard from „Balagrae” (El-Beida) and the earthquake of A. D. 365, w: Libya Antiqua III-IV, 1966-1967, 203-205. Enzo Catani datuje nawet schyłek istnienia Asklepieionu w Balagrae na początek VII wieku, zob. E. Catani, Il Santuario di Asclepio a Balagrae in: Cirene, Milano 2000, 183. 
przylegających w jednym szeregu do północnego boku portyku wielkiego perystylu kompleksu i były dostępne także tylko z tego portyku. Ustawione są one jeden za drugim w linii prostej, przecinającej pośrodku to pomieszczenie ze wschodu na zachód. Jego niewielkie rozmiary, tak jak dostęp doń z samego reprezentacyjnego centrum świętego kompleksu zdają się wykluczać, jeszcze dobitniej niż w poprzednich przypadkach, możliwość interpretacji obiektu jako stajni, w dodatku przeznaczonej tylko dla czterech koni. Wątpliwe jest równiez, aby instalacje te, znajdujące się w miejscu kultu Asklepiosa, służyły rozdawnictwu dóbr materialnych (ziarna, oliwek, czy innych owoców) potrzebującym przybyszom, bo ich potrzeby były zupełnie innego rodzaju. Wydaje się natomiast bardziej prawdopodobne, że mamy tu do czynienia z aktywnością mającą odwrotny kierunek, z gromadzeniem darów natury, ofiarowywanych bóstwu przez przybyszy, potrzebujących jego pomocy, co byłoby zresztą w tym miejscu całkiem zrozumiałe i logiczne. Bogata spuścizna epigraficzna z Asklepieionu w Pergamonie dostarcza nam całe mnóstwo informacji o tym, co i w jakich ilościach chorzy przybysze byli zobowiązani składać w ofierze Asklepiosowi lub dawali mu dobrowolnie, aby być w ogóle wpuszczonym jego świętego „kurortu”, nie mówiąc już o tym, ile byliby oni w stanie w ogóle mu ofiarować w nadziei na swoje wyzdrowienie ${ }^{16}$.

Zatem najbardziej prawdopodobną funkcją pierwotną „żłobów” w El Bayda byłoby gromadzenie w nich ofiar produktów naturalnych, przynoszonych przez chorych wyznawców boga Asklepiosa, przybyłych do jego sanktuarium w potrzebie zagrożonego zdrowia, czy wręcz dla uratowania życia.

Niestety nie mamy pewności, że podobnie było w domach w Ptolemais i Cyrene, bo jednak nie stanowiły one części kompleksów kościelnych. Najbliższe sąsiedztwo kościołów w obu przypadkach może, ale nie musi, wskazywać na to, że chrześcijanie udający się do kościołów zostawiali w miejscach do tego przeznaczonych w najbliższym sąsiedztwie miejsca kultu swoje ofiary, które tak czy inaczej byli zobowiązani przynosić. Szkopuł polega jednak na tym, że nie wiadomo, czy w domach tych mieszkali, lub choćby tylko urzędowali, przedstawiciele kościoła w Ptolemais i Cyrene. Paulos był w Ptolemais wysokim,

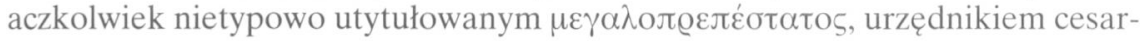
skim, ale inskrypcja ku jego czci została znaleziona zupełnie w innej części domu niż ,żłoby"17. Z planu domu Paulosa autorstwa Kraelinga, w ostatniej fazie jego aktywności wcale nie wynika, że obie te części domu stanowiły jedną całość $^{18}$. Natomiast drzwi na ulicę z pomieszczeń ze żłobami były usytuowane prawie naprzeciwko kościoła, aczkolwiek po drugiej stronie tej ulicy. Stosun-

${ }^{16}$ Por. M. Wörrle, w: Ch. Habicht, Die Inschriften des Asklepieions, Altertümer von Pergamon, VIII, 3, 1969, 167-190

${ }^{17}$ Por. Kraeling, Ptolemais, s. 211, odkryta w pomieszczeniu nr 1 na planie Kraelinga (tamże, s. 142, fig. 51).

${ }^{18}$ Por. tamże, s. 150, fig. 55. 
kowo niewielka pojemność ,żłobów” może, według mnie, wskazywać na to, że zbierano do nich na bieżąco ofiary, tzn. na czas ich złożenia, a potem przenoszono i gromadzono te dobra w miejscach i pojemnikach bardziej odpowiednich do ich przechowywania.

Przykłady ,żłobów” z Północnej Afryki stanowią tutaj tylko częściowo materiał porównawczy, bo takich kompleksów, niewątpliwie chrześcijańskich, czyli poświadczonych odpowiednimi inskrypcjami, jest bardzo niewiele. Bazylikalny plan tamtejszych budowli ze ,żłobami” - nawet trzy nawy z apsydą - nie stanowi, jak to dobitnie wykazał Noël Duval, jakiejkolwiek wskazówki w tym względzie, tzn. że mamy w takim przypadku do czynienia z kościołami. Jako przykłady chrześcijańskie - ale używane tylko przez chrześcijan niekoniecznie w celach kultowych - można wyodrębnić zaledwie cztery budowle ze „żłobami” wśród kilkunastu innych znanych takich kompleksów z obszaru całej Afryki Północnej. Byłyby to przykłady: w Henchir Faraoun - tzw. Bazylika w forcie bizantyjskim $^{19}$, w Zana - budowla na forum ${ }^{20}$, w Bulla Regia - tzw. kaplica księdza Aleksandra ${ }^{21}$ i w Kartaginie - Memoria siedmiu mnichów z Gafsy ${ }^{22}$. Według N. Duvala, nic w żadnej z tych budowli nie wskazuje na jednoznaczną funkcję ,żłobów”; podobnie ostrożnie w tym względzie wypowiada się Karmańska. Sądzę jednak, że kontekst archeologiczny „żłobów” w Henchir Faraon (silosy) i w Bulla Regia (amfory z resztkami produktów spożywczych), wskazuje na podobną funkcję ,żłobów”, jaką proponowałabym dla trzech przedstawionych tutaj przykładów z Cyrenaiki - czyli dla gromadzenia darów, czy danin, czy też ofiar chrześcijan. W Kartaginie brak jest takich śladów w kontekście archeologicznym, ale tamtejszy locus sanctus, w którym czczono siedmiu mnichów z Gafsy, mógł być celem pielgrzymek wiernych, którzy mogli również przynosić ze sobą dary z takimi samymi intencjami, jak robili to pobożni poganie przybywający do Asklepieionu w Balagrae w Cyrenaice.

${ }^{19}$ Por. Guénin, Notice sur l'Henchir-el-Begueur et résultat des fouilles opérées dans un fort byzantin englobant une basilique, „Bulletin Archéologique du Comité des Travaux Historiques et Scientifiques” 1907, 336-353; Karmańska, Le strutture dette „mangiatoie” in edifici, s. 6-8.

${ }^{20}$ Por. M. Christofle, Zana, Diana Veteranorum, in: Rapport sur les travaux de fouilles et consolidations effectués en 1930-1931 par le Service des Monuments Historiques de l'Algérie, Alger 1935, 176-183; Karmańska, Le strutture dette „mangiatoie” in edifici, s. 23-26.

21 Por. L. Carton, L'glise du prêtre Alexander découverte à Bulla Regia en 1914, „Comptes rendus de l'Académie des Inscriptions et Belles-Lettres" 1915, 116-130; A. Bechaouch - R. Hanoune - Y. Thebert, Les ruines de Bulla Regia, Rome 1977, 115-117; Karmańska, Le strutture dette , mangiatoie” in edifici, s. 32-35.

22 Por. L. Ennabli, Carthage. Une métropole chrétienne du IV siècle à la fin du VII siècle, Paris 1997, 89-100; zob. też recenzję tej książki N. Duvala: L'état des recherches archéologiques sur Carthage chrétienne, „Antiquité Tardive” 5 (1997) 328-334; L. Ennabli, La basilique de Carthagenna et le locus des sept moines de Gafsa: nouveaux édifices chrétiens de Carthage, Paris 2000, 120 126; por. też następną recenzję tej książki N. Duvala: „Antiquité Tardive” 8 (2000) 389-391; Karmańska, Le strutture dette „mangiatoie” in edifici, s. 35-39. 
Zostałoby zatem jeszcze zadanie dla patrologów, a mianowicie pracowita kwerenda źródłowa na temat formy i sposobów gromadzenia darów/ofiar wiernych przez przedstawicieli Kościołów afrykańskich od Numidii po Cyrenaikę, na szczęście w odniesieniu do dość ograniczonego czasowo okresu od IV po VI wiek.

\section{RESTI MATERIALI DELLE OFFERTE OPPURE DEI DONI ECCLESIASTICI NELLE CASE VICINE ALLE CHIESE A TOLEMAIDE E CIRENE?}

(Riassunto)

Si tratta di così dette mangiatoie di pietra, conservate nelle due case tardo antiche di Cirenaica (oggi Libia): casa di Paulos a Tolemaide (6 esemplari) e in una casa anonima ( 9 esemplari) presso la Basilica Centrale a Cirene. La più problematica sarebbe la funzione originaria di questi blocchi rettangolari di pietra ricavati dentro e messi in linea, perché gli studi precedenti di molti monumenti simili dell'Africa del Nord (oggi Tunisia e Algeria) non danno la risposta definitiva a questa domanda: se si tratterebbe delle vere mangiatoie per i cavalli oppure dei recipienti per l'annona in natura oppure, nei casi di ambienti cristiani con le „mangiatoie", dei recipienti per le offerte di terra dalla parte dei fedeli o per i doni a loro dalla parte della chiesa ai fedeli furono le vere stalle. Le installazioni di Cirenaica, insieme con le „mangiatoie" del Santuario d'Asclepio di El Bayda, non sono ancora conosciute ne pubblicate, sicuramente non hanno servito ai cavalli. L'ultimo caso sembra il più chiaro, ed è molto probabile che nelle "mangiatoie" del luogo deponevano le loro offerte portate al dio della Salute dai malati visitatori del santuario. Si può chiedere se la vicinanza stretta delle chiese, sia a Tolemaide, sia a Cirene, non potrebbe indicare la funzione simile delle „mangiatoie" in queste città antiche. Purtroppo le fonti scritte cristiane a questo proposito ne taccino oppure non sono ancora scoperte e studiate. 


\section{ILUSTRACJE}

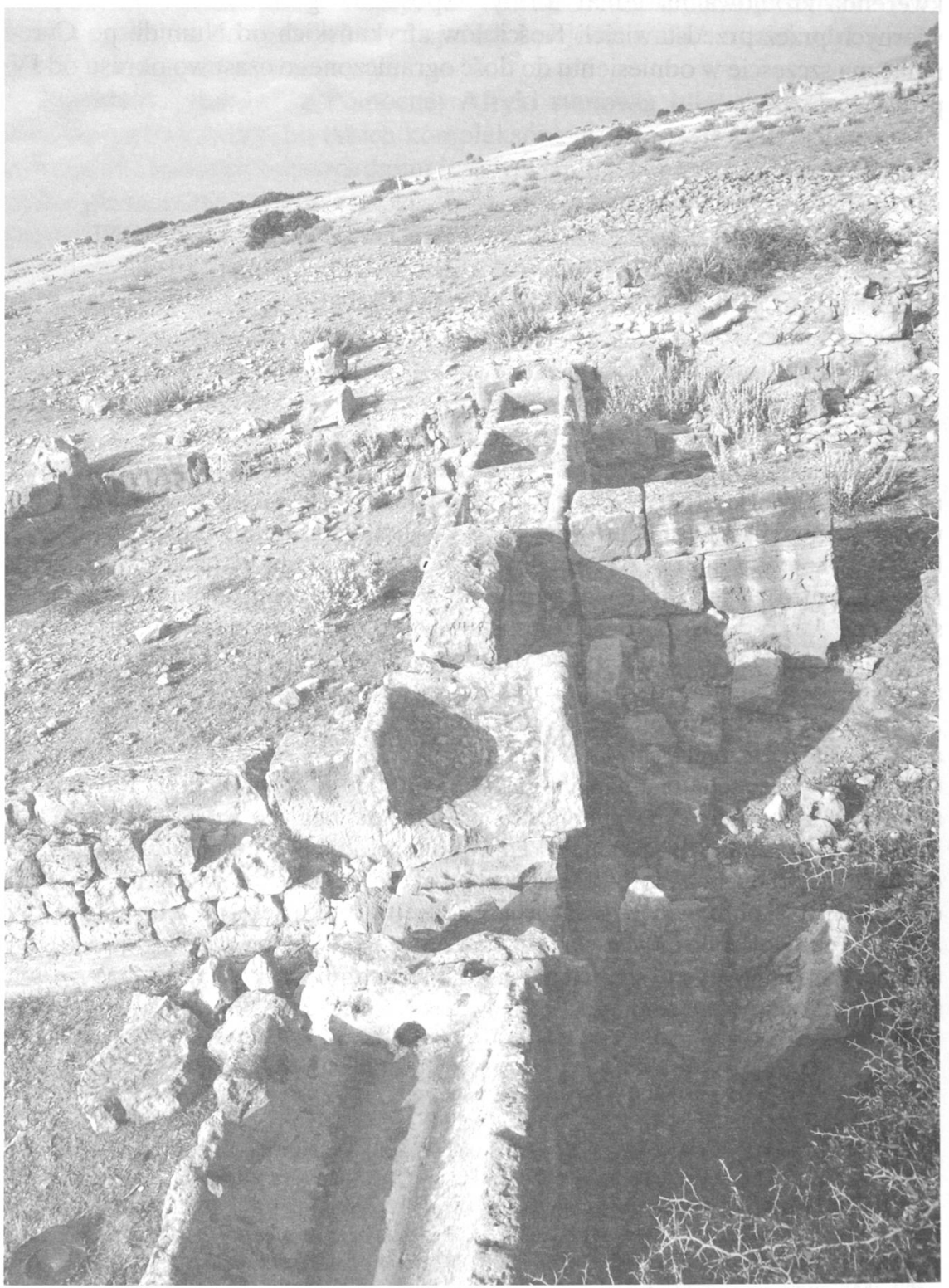

Il. 1. Rząd pięciu ,żłobów” w Domu Paulosa w Ptolemais, widok z zachodu na wschód (fot. autorka). 


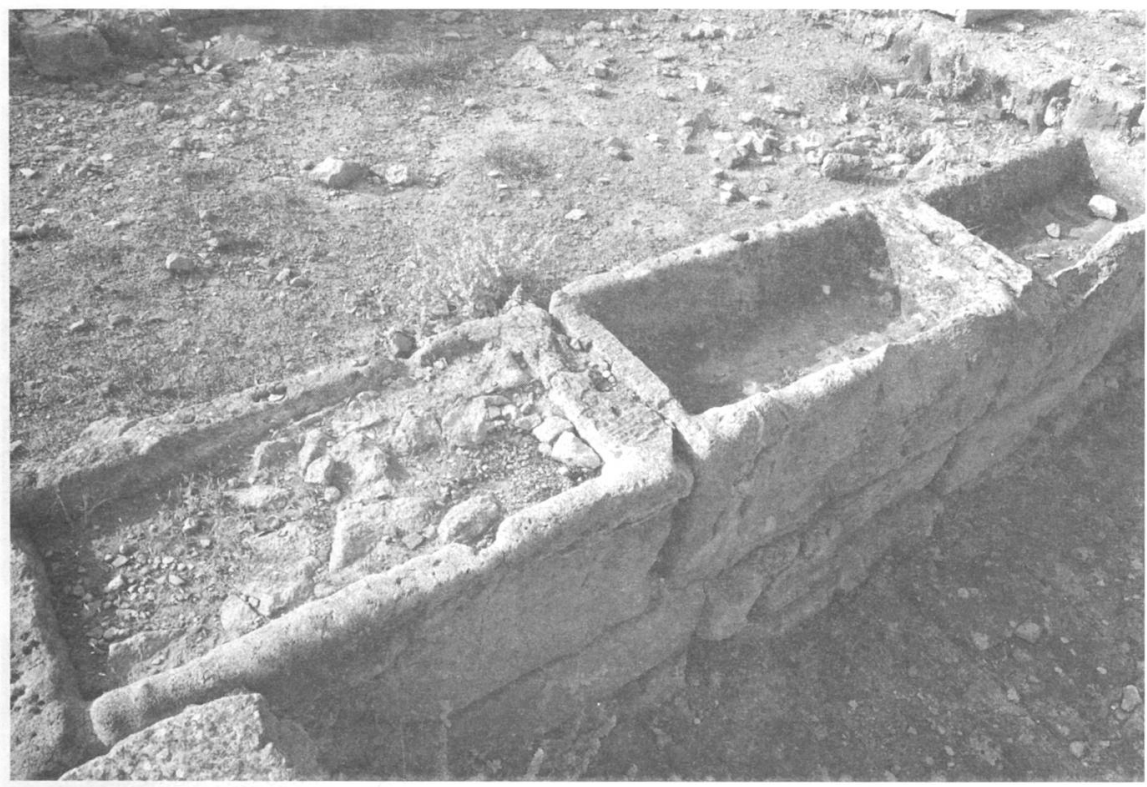

Il. 2. Trzy przykłady ,żłobów” w Domu Paulosa w Ptolemais, widok od południa (fot. autorka).

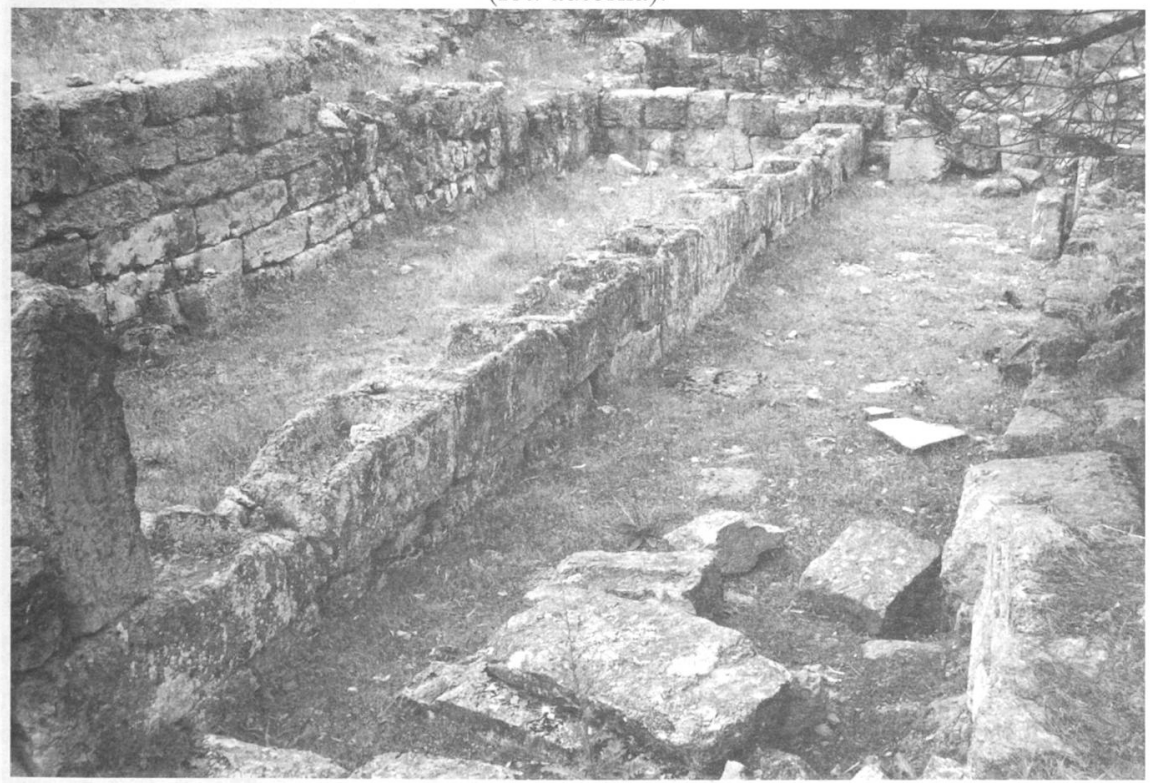

Il. 3. Rząd dziewięciu ,żłobów” w Domu Rzymskim w Cyrene, widok z północnego wschodu (fot. autorka). 


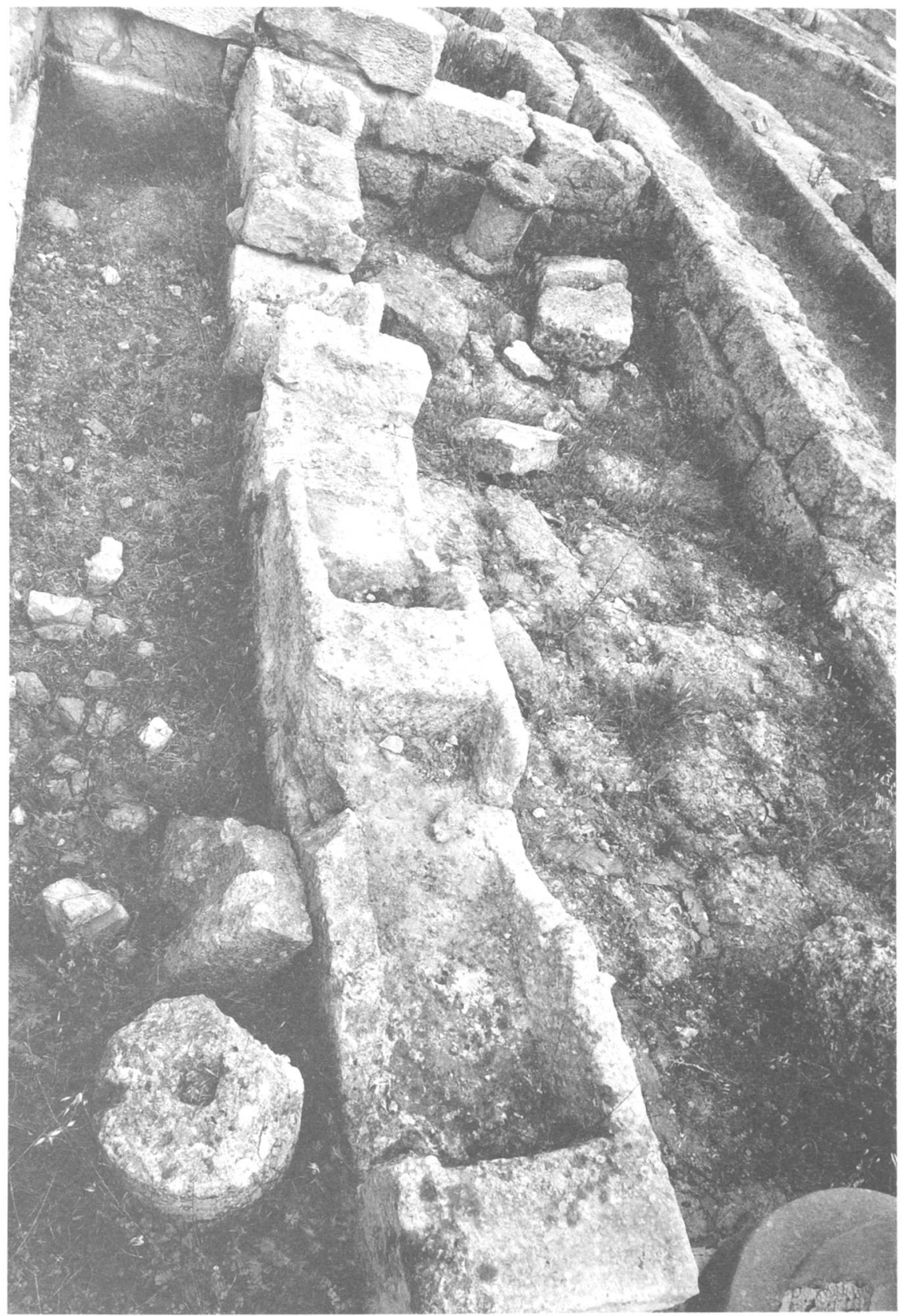

Il. 4. Cztery „żłoby” w Asklepiejonie w El Bayda, widok z zachodu (fot. autorka). 